\title{
Everolimus in Postmenopausal, Hormone Receptor- Positive Advanced Breast Cancer: Summary and Results of an Austrian Expert Panel Discussion
}

\author{
Michael Gnant ${ }^{\mathrm{a}}$ Richard Greil ${ }^{\mathrm{b}}$ Michael Hubalek ${ }^{\mathrm{c}}$ Günther Steger ${ }^{\mathrm{d}}$ \\ aComprehensive Cancer Center Vienna MUW/AKH, Universitätsklinik für Chirurgie, Medizinische Universität Wien, \\ bUniversitätsklinik für Innere Medizin III mit Hämatologie, internistischer Onkologie, Hämostaseologie, Infektiologie, Rheumatologie und \\ Onkologisches Zentrum, Paracelsus Medizinische Privatuniversität Salzburg, \\ 'Universitätsklinik für Frauenheilkunde, Medizinische Universität Innsbruck, \\ dUniversitätsklinik für Innere Medizin I, Medizinische Universität Wien, Austria
}

\section{Keywords}

Advanced breast cancer - Endocrine therapy .

Endocrine resistance $\cdot \mathrm{mTOR}$ inhibition - Everolimus .

Exemestane

\section{Summary}

In patients with hormone receptor-positive advanced breast cancer, response to endocrine therapy is frequently limited by endocrine resistance. One important mechanism of resistance is related to mammalian target of rapamycin (mTOR), a molecule involved in the activation of alternative signaling pathways. Preclinically, resensitization of endocrine resistance can be achieved by the addition of the mTOR inhibitor everolimus to endocrine therapy. Recent results of clinical trials confirmed the clinical activity of combining everolimus and endocrine therapy in neoadjuvant and advanced breast cancer. The BOLERO-2 trial demonstrated significant progression-free survival benefits for the addition of everolimus to exemestane. These data were the basis for the recent approval of everolimus in combination with exemestane for the treatment of advanced hormone receptor-positive breast cancer. In clinical practice, the following 3 patient groups are particularly suitable for this treatment: those with progression on aromatase inhibitor therapy, those who respond well to chemotherapy and might benefit from subsequent endocrine therapy, and those with non-aggressive tumor biology. Everolimus treatment requires careful clinical monitoring due to the potentially serious side effects, e.g. stomatitis and pneumonitis. It is also important to educate patients and physicians in order to increase their awareness of side effects. At present, everolimus is investigated in clinical trials.

\author{
Schlüsselwörter \\ Mammakarzinom, fortgeschrittenes · Endokrine Therapie . \\ Endokrine Resistenz · mTOR-Hemmung · Everolimus . \\ Exemestan
}

\section{Zusammenfassung}

Aufgrund von endokriner Resistenz sprechen Patientinnen mit Hormonrezeptor-positivem Mammakarzinom häufig nur bedingt auf antihormonelle Therapien an. Ein wichtiger Resistenzmechanismus wird durch mTOR (mammalian target of rapamycin) vermittelt, ein Molekül mit zentraler Funktion in der Aktivierung alternativer Signalwege innerhalb der Tumorzellen. Unter präklinischen Bedingungen kann durch den mTOR-Inhibitor Everolimus eine Resensibilisierung erreicht werden. Außerdem bestätigen klinische Studien die klinische Wirksamkeit der kombinierten Verabreichung von Everolimus und der endokrinen Therapie im neoadjuvanten und fortgeschrittenen Setting. Die Studie BOLERO-2 demonstrierte signifikante und relevante Verbesserungen des progressionsfreien Überlebens durch die Zugabe von Everolimus zu Exemestan. Diese Daten bilden die Basis für die kürzlich erfolgte Zulassung der Kombination aus Everolimus und Exemestan für die Behandlung des fortgeschrittenen Hormonrezeptor-positiven Mammakarzinoms nach dem Versagen von Aromatasehemmern. In der klinischen Praxis eignen sich 3 Patientinnengruppen besonders für diese Therapie: Patientinnen mit Progression unter Aromastasehemmern, solche mit gutem Ansprechen auf Chemotherapie und antihormonelle Folgetherapie sowie solche mit nicht aggressiver Tumorbiologie. Aufgrund der potenziell schweren Nebenwirkungen, z.B. Stomatitis und Pneumonitis, setzt die Therapie mit Everolimus eine sorgfältige klinische Überwachung voraus. Aufklärung und Bewusstseinsbildung hinsichtlich der Nebenwirkungen bei Ärzten und Patienten sind für ein optimales Therapiemanagement entscheidend. Derzeit wird Everolimus in weiteren klinischen Studien untersucht.

\section{KARGER \\ Fax +497614520714 \\ Information@Karger.com}

www.karger.com (c) 2013 S. Karger GmbH, Freiburg

$1661-3791 / 13 / 0084-0293 \$ 38.00 / 0$

Accessible online at:

www.karger.com/brc
Prof. Dr. med. Michael Gnant, M.D., FACS

Comprehensive Cancer Center Vienna

Medical University of Vienna - Department of Surgery

1090 Wien, Währinger Gürtel 18-20, Austria

michael.gnant@meduniwien.ac.at 


\section{Introduction}

It has been well documented that the mechanism of endocrine resistance is mainly driven by aberrant signaling along the phosphoinositide 3-kinase (PI3K) - Akt - mammalian target of rapamycin (mTOR) signaling pathway. mTOR is a Ser/Thr protein kinase that constitutes a central downstream part of this intracellular signaling pathway. Its activation enhances cell growth, proliferation and metabolism, and promotes angiogenesis [1]. The inhibition of the mTOR pathway by targeted therapies, such as everolimus or temsirolimus, can therefore block tumor growth and induce apoptosis [2]. In contrast to other mTOR-directed agents (dual mTOR complex 1/2 (mTORC1/2) inhibitors), everolimus has to be classified as a highly selective TORC1 inhibitor with respect to the feedback mechanism induced by the underlying mode of action. Everolimus shows activity in various malignant disease entities. In 2009, the European Medicines Agency (EMA) approved everolimus for the treatment of advanced renal cell carcinoma after failure of tyrosine kinase (e.g. sunitinib) therapy. 2 years later, approval was granted for the treatment of advanced pancreatic neuroendocrine tumors. The ongoing studies RECORD-2 and RECORD-3 will provide further data on the use of everolimus in renal cell carcinoma, as will RADIANT-4 for the indication of neuroendocrine tumors.

Most recently, everolimus was approved by the European authorities in combination with exemestane for the treatment of hormone receptor (HR)-positive, human epidermal growth factor receptor type 2 (HER2)-negative, advanced breast cancer in postmenopausal women without symptomatic visceral disease after recurrence or progression following a non-steroidal aromatase inhibitor (NSAI). In addition, a huge clinical trial program is ongoing to evaluate the efficacy of everolimus in HER2-positive breast cancer patients as well as in several other tumor entities (www.thewideprogram.com).

\section{Rationale for the Combination of Everolimus with Endocrine Therapy}

Failures in the treatment of patients with HR-positive breast cancer are linked to the development of resistance to endocrine treatment, possibly due to the activation of downstream signaling pathways like the mTOR cascade [3-5]. Also, the obtained responses sometimes last only for short periods of time. This implies endocrine resistance, which calls for strategies to overcome aberrant estrogen receptor (ER) signaling. Growing evidence supports close interactions and cross-talk between the mTOR pathway and ER signaling [6-8]. Resistance to endocrine therapy also suggests cross-talk between the ER and PI3K - Akt - mTOR pathways. S6 kinase 1 , a substrate of mTORC1, has been identified as a link between mTOR and ER signaling $[9,10]$. In addition, various feedback loops contribute to the close interactions of these two pathways. All of these considerations provide a solid rationale for the combination of an mTOR inhibitor with endocrine treatment to overcome endocrine resistance [11-13]. Nevertheless, tumor growth is not simply driven by one single signaling pathway, but is rather influenced by interactions and cross-talk of several different signaling cascades. Hence, these alternative signaling pathways are of great interest as they constitute potential targets for future combination partners of mTOR antagonists.

\section{Overview of Clinical Trials with Everolimus in Breast Cancer}

\section{Phase II: Letrozole \pm Everolimus}

\section{in the Neoadjuvant Setting}

The first phase II clinical trial to investigate everolimus in breast cancer patients was conducted in the neoadjuvant setting [14]. Within this trial, 270 postmenopausal women with ER-positive early breast cancer were randomized to either letrozole $2.5 \mathrm{mg}$ /day plus everolimus $10 \mathrm{mg} /$ day, or letrozole $2.5 \mathrm{mg} /$ day plus placebo. The study yielded encouraging results which demonstrated that the mTOR inhibitor is effective when added to endocrine therapy. The response rates were $68 \%$ and $59 \%$ in the combination and the single-agent group, respectively $(\mathrm{p}=0.062)$. Benefits for the addition of everolimus were also observed in terms of greater antiproliferative responses (Ki-67 down-regulation in $57 \%$ vs. $30 \%$ of patients $(\mathrm{p}<0.01))$.

\section{Phase II: Tamoxifen \pm Everolimus}

\section{in Advanced Breast Cancer}

In the open-label, tamoxifen plus everolimus (TAMRAD) phase II study conducted by the French study group GINECO, 111 postmenopausal patients with advanced ERpositive, HER2-negative breast cancer were randomly assigned to tamoxifen $20 \mathrm{mg}$ /day plus everolimus $10 \mathrm{mg}$ /day, or tamoxifen $20 \mathrm{mg} /$ day alone [15]. All of the patients had already received aromatase inhibitor (AI) therapy in the adjuvant or metastatic setting and had progressive disease. Patients treated with both tamoxifen and everolimus experienced significant benefits with regard to time to progression ( 8.6 vs. 4.5 months; $p=0.002$ ) and overall survival (not yet reached for everolimus vs. 32.9 months; $p=0.007$ ). The risk of progression and mortality was reduced by $46 \%$ (hazard ratio (HR) $0.54,95 \%$ confidence interval (CI) $0.36-0.81$ ) and $55 \%$ (HR 0.45, 95\% CI 0.24-0.81), respectively. The clinical benefit rates (CBR) after 6 months in the intention-to-treat population were estimated at $61 \%$ versus $42 \%(p=0.045)$. An exploratory subgroup analysis showed higher CBR in patients with secondary hormone resistance who received tamoxifen plus everolimus, as compared to the single-agent treatment (74\% vs. $48 \%$ ). Women with primary hormone resistance experienced only a slightly higher CBR with the combination 
(46\% vs. 36\%). For patients with disease measurable by Response Evaluation Criteria in Solid Tumors (RECIST), the response rates were $14 \%$ with tamoxifen plus everolimus and $13 \%$ in the tamoxifen-alone group.

\section{Pivotal Phase III Study: Exemestane \pm}

Everolimus in Advanced Breast Cancer

The double-blind, randomized Breast Cancer Trials of Oral Everolimus (BOLERO)-2 phase III study included 724 postmenopausal patients with ER-positive, HER2-negative breast cancer, at 189 centers in 24 countries. Patients were refractory to previous NSAI (letrozole or anastrozole) therapy, which was defined as recurrence during or within 12 months after the end of adjuvant treatment, or progression during or within 1 month after the end of treatment in the advanced setting. Overall, patients showed markedly advanced disease, with a moderate tumor burden and a favorable average performance status. The treatment consisted of exemestane $25 \mathrm{mg} /$ day plus everolimus $10 \mathrm{mg} /$ day, or exemestane $25 \mathrm{mg} /$ day plus placebo. The primary endpoint was progression-free survival (PFS); secondary endpoints included overall survival, overall response rate (ORR), and safety.

The superiority of the everolimus combination treatment was already evident at the first pre-planned interim analysis (after 359 PFS events) and was confirmed in the final analysis after 18 months of median follow-up. At the interim analysis, as assessed by the investigators, the median PFS was 6.9 versus 2.8 months in the everolimus combination and exemestanealone groups, respectively ( $\mathrm{p}<0.001$, HR 0.43 ; table 1) [16].
On the basis of central assessment, the median PFS was 10.6 versus 4.1 months $(\mathrm{p}<0.001)$, which translates into a $64 \%$ risk reduction. At 18 months, the investigators estimated the median PFS at 7.8 versus 3.2 months $(\mathrm{p}<0.0001$, HR 0.45 , 96\% CI 0.38-0.54); according to a central assessment, the PFS results were 11.0 versus 4.1 months $(\mathrm{p}<0.0001)$, translating into a $62 \%$ risk reduction (HR 0.38) [17].

PFS was significantly improved with everolimus across all prospectively defined subgroups, as stratified by age, region, baseline Eastern Cooperative Oncology Group (ECOG) performance status, sensitivity to previous hormonal therapy, presence of visceral metastasis, presence of measurable disease, number of previous therapies, type of most recent therapy, previous treatment with fulvestrant, previous chemotherapy, and progesterone receptor status. The fact that the activity of the everolimus combination treatment did not depend on the type of any previous hormonal treatment supports the rationale of this study and importantly highlights the reliability of the mechanism of action.

In addition, according to local assessments, partial responses were observed in $9.1 \%$ versus $0.4 \%$ in the combination and the exemestane-only groups, respectively $(\mathrm{p}<0.001)$. As expected, both groups showed low complete remission rates $(0.4 \%$ vs. $0 \%)$. Stable disease was achieved by a markedly higher proportion of women in the experimental arm (70.1\% vs. $58.6 \%$ ), whereas progressive disease occurred considerably less frequently in these patients $(9.9 \%$ vs. $31.4 \%)$. Overall survival results were immature at the cut-off date of the interim analysis (200 events had occurred, $25.4 \%$ for the

Table 1. Efficacy analysis on the basis of local and central assessment in BOLERO-2 [16]

\begin{tabular}{|c|c|c|c|c|c|}
\hline & Variable & $\begin{array}{l}\text { Everolimus and exemestane, } \\
\mathrm{n}=485\end{array}$ & $\begin{array}{l}\text { Placebo and exemestane, } \\
\mathrm{n}=239\end{array}$ & $\mathrm{p}$ Value & $\operatorname{HR}(95 \% \mathrm{CI})$ \\
\hline \multicolumn{6}{|c|}{ Local assessment } \\
\hline \multirow[t]{3}{*}{ PFS } & $\begin{array}{l}\text { events, } \mathrm{n}(\%) \\
\text { duration, months }\end{array}$ & $202(42)$ & $157(66)$ & $<0.001$ & $0.43(0.35-0.54)$ \\
\hline & median & 6.9 & 2.8 & & \\
\hline & $95 \% \mathrm{CI}$ & $6.4-8.1$ & $2.8-4.1$ & & \\
\hline \multirow{6}{*}{$\begin{array}{l}\text { Best overall } \\
\text { response, } \%\end{array}$} & complete response & 0.4 & 0.0 & & \\
\hline & partial response & 9.1 & 0.4 & & \\
\hline & stable disease & 70.1 & 58.6 & & \\
\hline & progressive disease & 9.9 & 31.4 & & \\
\hline & unknown or too early & 10.5 & 9.6 & & \\
\hline & $\begin{array}{l}\text { objective response, \% } \\
(95 \% \mathrm{CI})\end{array}$ & $9.5(7.0-12.4)$ & $0.4(0.0-2.3)$ & $<0.001$ & \\
\hline \multicolumn{6}{|c|}{ Central assessment } \\
\hline \multirow{2}{*}{ PFS } & median & 10.6 & 4.1 & & \\
\hline & $95 \% \mathrm{CI}$ & 9.5-NR & $2.8-5.8$ & & \\
\hline \multirow{6}{*}{$\begin{array}{l}\text { Best overall } \\
\text { response, \% }\end{array}$} & complete response & 0.0 & 0.0 & & \\
\hline & partial response & 7.0 & 0.4 & & \\
\hline & stable disease & 74.6 & 64.4 & & \\
\hline & progressive disease & 5.6 & 21.8 & & \\
\hline & unknown or too early & 12.8 & 13.4 & & \\
\hline & objective response & $7.0(4.9-9.7)$ & $0.4(0.0-2.3)$ & $<0.001$ & \\
\hline
\end{tabular}


everolimus arm and $32.2 \%$ for the exemestane-alone arm). For quality of life (QoL), the estimates revealed no significant differences; this is not surprising as many of the patients were asymptomatic. As adverse events also affect this outcome, it can be assumed that the patients' QoL was maintained and not adversely affected by the everolimus treatment.

\section{Positioning of Everolimus plus Endocrine Therapy in the Current Treatment Concept}

To date, phase III evidence on the combination of everolimus and exemestane has been obtained in the advanced setting, in postmenopausal women with HR-positive, HER2negative breast cancer after NSAI treatment. Therefore, valid recommendations cannot be given for other treatment settings. Further trials are ongoing and will provide more data in due time over the course of the next 2 years. Previous NSAI therapy in the adjuvant or metastatic setting is thus mandatory before prescribing the everolimus and exemestane combination.

The distinct overall advantage of this regimen lies in the delay of tumor progression since 'breaking resistance' is conceptually not a strategy particularly suitable for the achievement of remission. However, delay of progression constitutes an important treatment target in itself.

Clinical Conclusions Reached by the Austrian Expert Panel

Three groups of patients are most likely to derive benefits from the combination treatment of exemestane with everolimus. The first group comprises those who progress while on treatment with an AI in the metastatic setting. Immediate initiation of treatment with exemestane plus everolimus in this setting is indicated. This recommendation is in line with the basic principle of applying the most efficacious treatment as early as possible, and with the indication as defined in the BOLERO-2 trial.

The second group of patients who are likely to derive benefit from everolimus comprise those with indolent and/or smouldering disease, with low tumor burden and long tumorfree intervals (late relapses).

Finally, the third group includes patients after chemotherapy treatment; here, the combination with everolimus is certainly a major option in the maintenance setting when endocrine therapy is indicated; there is, however, no evidence for maintenance therapy of everolimus by itself, so far.

As there are no recommendations on the sequence of hormonal agents, specific treatment choices have to be made on an individual basis. For instance, due to its non-oral administration route, fulvestrant might be preferable in patients with a history of or factors pointing towards poor compliance. Also, at the psychological level, switching to a new drug may meet stronger acceptance in a patient than the represcription of a drug (as part of a combination treatment) that this patient

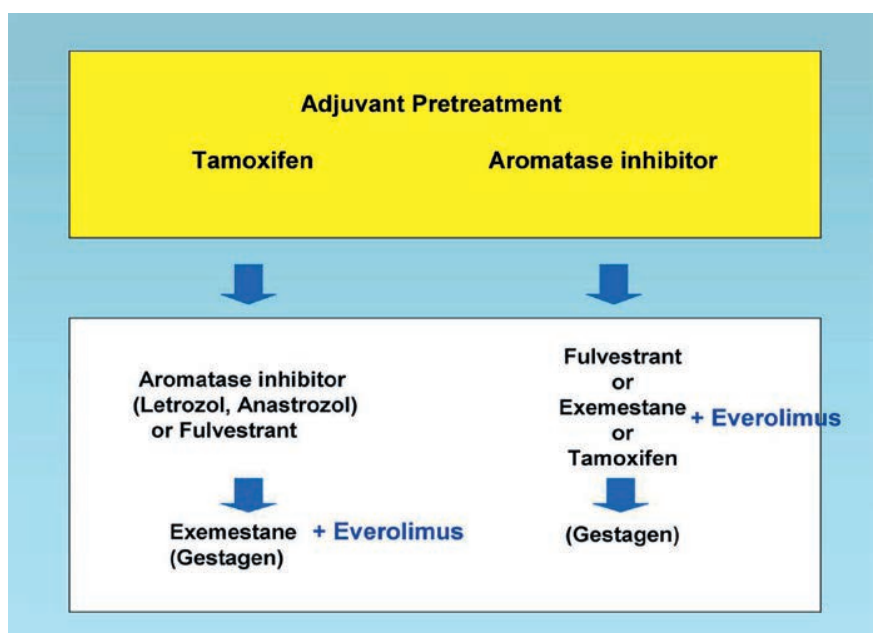

Fig. 1. Pallative endocrine therapy of postmenopausal HR-positive breast cancer $[18,19]$.

has been resistant to in the past. Issues of toxicity should also be taken into consideration, especially in the palliative setting.

Based on the new evidence, the palliative hormonal therapy algorithm in postmenopausal women with HR-positive, HER2-negative breast cancer can be modified as depicted in figure 1. Depending on the adjuvant pretreatment, NSAIs, fulvestrant, exemestane or tamoxifen are recommended as sequential treatment options $[18,19]$. When exemestane is an option, the addition of everolimus should be discussed.

As with the other targeted therapies, not all of the patients can be expected to respond to the new treatment combination. Patients will always display different clinical courses, in spite of seemingly identical molecular characteristics of their disease. Research findings even demonstrate the existence of intratumor heterogeneity: Gerlinger et al. [20] detected different gene expression patterns in different regions of the same tumor. This suggests that extrapolation of results from a single biopsy might be problematic and that tumor adaptation and therapeutic failure through Darwinian selection is an issue. Various resistance patterns are being developed at the genomic level in the course of tumor progression.

\section{Safety Aspects}

All of the phase III trials with everolimus conducted to date, in a total of more than 4000 patients with various tumor entities, have shown similar safety results that were in accordance with the expected safety profile of this drug. Adverse events (AEs) of everolimus are well documented and manageable. The most common AEs of everolimus (reported in $>25 \%$ of patients) are: stomatitis, rash, fatigue, diarrhea, nausea, decreased appetite, weight loss, cough, non-infectious pneumonitis, and hyperglycemia. Patient awareness and early 
intervention are, however, crucial. Prophylactic approaches and adequate therapy management can help to minimize side effects such as stomatitis or skin rash. After all, the studies conducted with everolimus haven given rise to a large number of safety concerns (see above).

In BOLERO- $2,8 \%$ of the patients in the combination arm discontinued treatment due to AEs, whereas this was true for only $3 \%$ of those who received single-agent exemestane (everolimus $19 \%$ vs. placebo $4 \%$; exemestane $7 \%$ in the combination and exemestane $3 \%$ in the alone arm). Due to its mode of action (immunosuppressive properties), everolimus can promote infections, including those due to opportunistic pathogens, such as Aspergillus and Candida. Hepatitis B and $\mathrm{C}$ infections can flare up or be reactivated. Stomatitis is among the most common AEs experienced by patients who receive mTOR inhibitors. Likewise, non-infectious pneumonitis has been identified as a class effect of rapamycin derivatives. Symptomatic pneumonitis cases are usually mild to moderate and reversible. However, some are severe and fatal. Acneiform dermatitis, which is bothersome rather than dangerous, occurred in $36 \%$ of patients in the BOLERO-2 trial. Metabolic AEs of everolimus include hyperglycemia and hyperlipidemia. Serum creatinine elevations, proteinuria, and renal failure (including acute renal failure) occurred infrequently. Nonetheless, some cases of renal failure have been fatal.

Adequate management of these AEs is vital to avoid serious complications, to preserve the QoL and to ensure treatment adherence. Before treatment is initiated, obtaining a thorough medical history of prior infections and pulmonary conditions is essential. Everolimus should not be used in patients with severe chronic obstructive pulmonary disease or significant pulmonary fibrosis. Optimal glycemic control should be achieved before starting a patient on everolimus. Everolimus treatment requires regular monitoring of hemoglobin A1c (HbA1c) and fasting serum glucose levels, lipid levels, markers of renal function including blood urea nitrogen, urinary protein and serum creatinine, and blood cell counts. In addition to specific measures, dose reductions or even discontinuation of everolimus therapy can be necessary for the management of AEs: In case of mild AEs (less than World Health Organization (WHO) grade III), dose reduction to $5 \mathrm{mg}$ should be considered. In the BOLERO-2 trial, there was no difference in everolimus efficacy, irrespective of dose reductions ([17]; median dose $>7.5 \mathrm{mg}$ vs. $\leq 7.5 \mathrm{mg}$ ).

Patient awareness and early intervention are absolutely crucial. Patients should be informed about their increased susceptibility to certain complications while on treatment with everolimus, and about the nature of signs and symptoms that should cause them to report immediately to the clinic where they are being treated. The management of these toxicities should be restricted to health care professionals with appropriate expertise. Awareness is therefore also pivotal among physicians. Educational activities will be conducted alongside the clinical trials. The U.S. Food and Drug Administration (FDA) advised on July 20, 2012: 'Patients aged 65 years and older should be monitored closely as these patients experience a higher rate of serious side effects than younger patients receiving treatment.' As everolimus is metabolized via cytochrome P450 3A4 (CYP3A4), drug interactions can occur. Concomitant use of potent CYP3A4/P-glycoprotein (PgP) inhibitors, such as ketoconazole or ritonavir, should be avoided. Indeed, caution is recommended even with moderate inhibitors (e.g. erythromycin, verapamil, aprepitant). This also applies to potent CYP3A4 inducers such as rifampicin or corticosteroids; dose increases should be considered when these drugs are used together with everolimus.

\section{Outlook}

Everolimus is currently also being assessed in patients with HR-positive, HER2-positive advanced breast cancer in 2 phase III trials. BOLERO-1 is investigating first-line trastuzumab plus paclitaxel with or without everolimus [21], while BOLERO-3 is evaluating the efficacy of trastuzumab plus vinorelbine with or without everolimus in the second-line/ third-line setting [22]. In both studies, treatment is administered until progression or unacceptable toxicity, and PFS is defined as the primary endpoint. Analyses will be available within the next 2 years. Data on biomarkers that will allow for patient selection are being collected within all of the trials, although to date no marker has been identified that allows for the selection of patients for everolimus treatment.

Also, it has been shown that everolimus can reverse bone loss associated with estrogen deprivation [23]. mTOR inhibition decreases bone resorption as well as osteoclast maturation, and increases osteoclast apoptosis in the mouse model [24]. Bone turnover marker data collected retrospectively in BOLERO-2 also suggest beneficial effects of everolimus on bone health [25-27]. Whereas in the exemestane-only group bone turnover marker levels increased as compared to baseline at 6 and 12 weeks, decreases or no changes were observed in the combination arm. This was true irrespective of the presence of bone metastases or bisphosphonate use at baseline. Moreover, disease progression in bone was decreased by the addition of everolimus both in the overall population and in the large group of patients with bone metastases at baseline.

\section{Discussion}

Even though the regimen of everolimus combined with exemestane has certain limitations, the introduction of the mTOR inhibitor can be regarded as a breakthrough in the treatment of patients with advanced breast cancer. Everolimus is the first agent to enhance the clinical benefit of hormonal therapy when administered concomitantly in patients 
with HR-positive, HER2-negative advanced breast cancer after NSAI failure. Resistance to endocrine therapy can be overcome by the inhibition of mTOR, as this component is crucially involved in the activation of an alternative signaling pathway to the one that is driven by stimulation of the hormonal receptor. Positive results of the BOLERO-2 trial are consistent with the findings of 2 other studies of everolimus and anti-estrogen therapy in patients with HR-positive breast cancer. Everolimus in the treatment of HR-positive, HER2negative advanced breast cancer significantly improves PFS, corresponding to a $55 \%$ risk reduction, which was consistent across all patient subgroups. The combination regimen also offers the advantages of oral administration.

On the other hand, oral application means that adherence can be an issue, all the more because 2 different drugs have to be taken every day. Furthermore, the management of side effects is crucial in this respect. Clinical studies have revealed a set of potentially serious AEs of everolimus that require close monitoring and treatment by experienced physicians. It is of paramount importance to inform patients about warning signs that might call for medical attention. However, when careful patient selection and treatment are brought to bear, substantial improvements of the clinical course of the disease can be expected.

The therapeutic principle of mTOR inhibition is already established in the management of several tumor entities such as pancreatic neuroendocrine tumors and renal cell carcinoma, yet research has really only just begun in this field. Everolimus is currently under investigation in several entities based on its biological rationale, and various studies are ongoing. In the treatment of breast cancer, the combination of everolimus and exemestane is assumed to have beneficial effects in settings other than those assessed to date, but phase III data are so far only available on advanced HER2-negative disease. For this reason, current treatment recommendations are restricted to patients with characteristics equivalent to the inclusion criteria of BOLERO-2. The final results of the ongoing BOLERO-1 and BOLERO-3 phase III trials will, however, be released over the next 2 years, which will probably change the picture in a profound way. The adjuvant SWOG and French trials have been launched and will provide information on the use of everolimus together with endocrine therapy in the early breast cancer setting. Overall, this regimen adds to the hitherto largely successful efforts of turning breast cancer into a chronic disease with a good QoL and a reasonable life expectancy.

\section{Disclosure Statement}

M.G. reports to have received research support from Glaxo-SmithKline, Sanofi-Aventis, Novartis, and Roche. He has served as consultant for Merrion and Novartis, and has received honoraria (speaking, advisory boards, etc.) and travel support from Amgen, Pfizer, Novartis, GlaxoSmithKline, Bayer, Sandoz, AstraZeneca, and GenomicHealth. G.G.S. reports to have received lecture fees, advisory board fees, travel grants, and meeting grants from Amgen, Roche Austria, Hoffmann La-Roche, Sanofi-Aventis, AstraZeneca, GlaxoSmithKline, Novartis, Cephalon, and Eisai, and lecture fees from EBEWE and Pfizer. M.H. reports to have received lecture fees, advisory board fees, and travel grants from Novartis, Roche, and Amgen. R.G. reports to have received advisory board fees and research support from Novartis and AstraZeneca, and speaker's honoraria from Novartis.

\section{References}

1 Moy B, Goss PE: Estrogen receptor pathway: resistance to endocrine therapy and new therapeutic approaches. Clin Cancer Res 2006;12:47904793.

2 Pópulo H, Lopes JM, Soares P: The mTOR signalling pathway in human cancer. Int J Mol Sci 2012; 13:1186-1198

$>3$ Burstein HJ: Novel agents and future directions for refractory breast cancer. Semin Oncol 2011; 38(suppl 2):S17-S24.

4 Johnston SR: Clinical efforts to combine endocrine agents with targeted therapies against epidermal growth factor receptor/human epidermal growth factor receptor 2 and mammalian target of rapamycin in breast cancer. Clin Cancer Res 2006;12: 1061S-1068S.

${ }_{5}$ Schiff R, Massarweh SA, Shou J, Bharwani L, Mohsin SK, Osborne CK: Crosstalk between estrogen receptor and growth factor pathways as a molecular target for overcoming endocrine resistance. Clin Cancer Res 2004;10:331S-336S

6 Yue W, Fan P, Wang J, Li Y, Santen RJ: Mechanisms of acquired resistance to endocrine therapy in hormone-dependent breast cancer cells. J Steroid Biochem Mol Biol 2007;106:102-110.

7 Miller TW, Hennessy BT, González-Angulo AM, Fox EM, Mills GB, Chen H, Higham C, García-
Echeverría C, Shyr Y, Arteaga CL: Hyperactivation of phosphatidylinositol-3 kinase promotes escape from hormone dependence in estrogen receptor-positive human breast cancer. J Clin Invest 2010;120:2406-2413.

8 Santen RJ, Song RX, Zhang Z, Kumar R, Jeng MH, Masamura S, Lawrence J Jr, MacMahon LP, Yue W, Berstein L: Adaptive hypersensitivity to estrogen: mechanisms and clinical relevance to aromatase inhibitor therapy in breast cancer treatment. J Steroid Biochem Mol Biol 2005:95:155165.

9 Yamnik RL, Holz MK: mTOR/S6K1 and MAPK/ RSK signaling pathways coordinately regulate estrogen receptor alpha serine 167 phosphorylation. FEBS Lett 2010;584:124-128.

10 Yamnik RL, Digilova A, Davis DC, Brodt ZN, Murphy CJ, Holz MK: S6 kinase 1 regulates estrogen receptor alpha in control of breast cancer cell proliferation. J Biol Chem 2009;284:6361-6369.

11 DeGraffenried LA, Friedrichs WE, Russell DH, Donzis EJ, Middleton AK, Silva JM, Roth RA, Hidalgo M: Inhibition of mTOR activity restores tamoxifen response in breast cancer cells with aberrant Akt activity. Clin Cancer Res 2004;10: 8059-8067.
12 Boulay A, Rudloff J, Ye J, Zumstein-Mecker S, O'Reilly T, Evans DB, Chen S, Lane HA: Dual inhibition of mTOR and estrogen receptor signaling in vitro induces cell death in models of breast cancer. Clin Cancer Res 2005;11:5319-5328.

13 Beeram M, Tan QT, Tekmal RR, Russell D, Middleton A, DeGraffenried LA: Akt-induced endocrine therapy resistance is reversed by inhibition of mTOR signaling. Ann Oncol 2007;18:13231328.

14 Baselga J, Semiglazov V, van Dam P, Manikhas A, Bellet M, Mayordomo J, Campone M, Kubista E, Greil R, Bianchi G, Steinseifer J, Molloy B, Tokaji E, Gardner H, Phillips P, Stumm M, Lane HA, Dixon JM, Jonat W, Rugo HS: Phase II randomized study of neoadjuvant everolimus plus letrozole compared with placebo plus letrozole in patients with estrogen receptor-positive breast cancer. J Clin Oncol 2009;27:2630-2637.

15 Bachelot T, Bourgier C, Cropet C, Ray-Coquard I, Ferrero JM, Freyer G, Abadie-Lacourtoisie S, Eymard JC, Debled M, Spaëth D, Legouffe E, Allouache D, El Kouri C, Pujade-Lauraine E: Randomized phase II trial of everolimus in combination with tamoxifen in patients with hormone receptor-positive, human epidermal growth factor receptor 2-negative metastatic breast cancer with 
prior exposure to aromatase inhibitors: a GINECO study. J Clin Oncol 2012; 30:2718-2724.

16 Baselga J, Campone M, Piccart M, Burris HA 3rd, Rugo HS, Sahmoud T, Noguchi S, Gnant M, Pritchard KI, Lebrun F, Beck JT, Ito Y, Yardley D, Deleu I, Perez A, Bachelot T, Vittori L, Xu Z, Mukhopadhyay P, Lebwohl D, Hortobagyi GN: Everolimus in postmenopausal hormone-receptor-positive advanced breast cancer. N Engl J Med 2012;366:520-529.

17 Piccart-Gebhart MJ, Noguchi S, Pritchard KI, Burris HA, Rugo HS, Gnant M, Hortobagyi GN, Melichar B, Petrakova K, Arena FP, Xu C, Cahana A, Taran T, Sahmoud T, Lebwohl DE, Campone M, Baselga J: Everolimus for postmenopausal women with advanced breast cancer: updated results of the BOLERO-2 phase III trial. J Clin Oncol 2012;30(suppl):abstr 559

18 Beslija S, Bonneterre J, Burstein H, Cocquyt V, Gnant M, Goodwin P, Heinemann V, Jassem J, Köstler WJ, Krainer M, Menard S, Petit T, Petruzelka L, Possinger K, Schmid P, Stadtmauer E, Stockler M, Van Belle S, Vogel C, Wilcken N, Wiltschke C, Zielinski CC, Zwierzina H: Second consensus on medical treatment of metastatic breast cancer. Ann Oncol 2007;18:215-225.

19 Beslija S, Bonneterre J, Burstein HJ, Cocquyt V, Gnant M, Heinemann V, Jassem J, Köstler WJ, Krainer M, Menard S, Petit T, Petruzelka L, Possinger K, Schmid P, Stadtmauer E, Stockler M, Van Belle S, Vogel C, Wilcken N, Wiltschke C, Zielinski CC, Zwierzina H; Central European Cooperative Oncology Group (CECOG): Third consensus on medical treatment of metastatic breast cancer. Ann Oncol 2009;20:1771-1785.

20 Gerlinger M, Rowan AJ, Horswell S, Larkin J, Endesfelder D, Gronroos E, Martinez P, Matthews N, Stewart A, Tarpey P, Varela I, Phillimore B, Begum S, McDonald NQ, Butler A, Jones D, Raine K, Latimer C, Santos CR, Nohadani M, Eklund AC, Spencer-Dene B, Clark G, Pickering L, Stamp G, Gore M, Szallasi Z, Downward J, Futreal PA, Swanton C: Intratumor heterogeneity and branched evolution revealed by multiregion sequencing. N Engl J Med 2012;366:883-892.

21 Everolimus in combination with trastuzumab and paclitaxel in the treatment of HER2 positive locally advanced or metastatic breast cancer (BOLERO 1) http://clinicaltrials.gov/show/NCT00876395.

22 Daily everolimus in combination with trastuzumab and vinorelbine in HER2/neu positive women with locally advanced or metastatic breast cancer (BOLERO-3). http://clinicaltrials.gov/show/NCT01007942.

23 Kneissel M, Luong-Nguyen NH, Baptist M, Cortesi R, Zumstein-Mecker S, Kossida S, O'Reilly T, Lane H, Susa M: Everolimus suppresses cancellous bone loss, bone resorption, and cathepsin K expression by osteoclasts. Bone 2004: 35:1144-1156

24 Glantschnig H, Fisher JE, Wesolowski G, Rodan GA, Reszka AA: M-CSF, TNFalpha and RANK ligand promote osteoclast survival by signaling through mTOR/S6 kinase. Cell Death Differ 2003;10:1165-1177.

25 Gnant M, Hortobagyi GN, Rugo HS, Burris HA, Noguchi S, Pritchard KI, Baselga J, Sahmoud T, Bauly H, Piccart M: Everolimus added to exemestane reduced bone turnover marker levels and disease progression in bone in postmenopausal women with advanced breast cancer: updated results from the BOLERO-2 trial. Presented at the 8th European Breast Cancer Conference, 21-24 March 2012, Vienna; abstr 3LBA.

26 Gnant M, Baselga J, Rugo HS, Noguchi S, Pritchard KI, Burris HA, PiccartGebhart MJ, Hart LL, Eakle JF, Mukai H, Iwata H, El-Hashimy M, Rao S, Taran T, Sahmoud T, Lebwohl DE, Hortobagyi GN: Effects of everolimus (EVE) on disease progression in bone and bone markers (BM) in patients (pts) with bone metastases (mets). J Clin Oncol 2012:30(suppl);abstr 512.

-27 Gnant M, Baselga J, Rugo HS, Noguchi S, Burris HA, Piccart M, Hortobagyi GN, Eakle J, Mukai H, Iwata H, Geberth M, Hart LL, Hadji P, El-Hashimy M, Rao S, Taran T, Sahmoud T, Lebwohl D, Campone M, Pritchard KI: Everolimus reduced bone marker levels and progressive disease in bone in BOLERO-2. J Natl Cancer Inst 2013;105:654-663. 